\title{
Aminoglycoside cross-resistance patterns of gentamicin-resistant bacteria
}

\author{
ELIZABETH T. HOUANG ${ }^{1}$ AND DAVID GREENWOOD 2 \\ From the Department of Medical Microbiology, St. Bartholomew's Hospital, West Smithfield, London \\ EC1A $7 B E$
}

SUMmARY Ten strains each of Escherichia coli, Staphylococcus aureus, and Pseudomonas aeruginosa were habituated to gentamicin by serial passage in antibiotic containing medium. Complete crossresistance to streptomycin, neomycin, kanamycin, and tobramycin in a linear proportional fashion was demonstrated at all stages of habituation. Most strains of Staph. aureus and Ps. aeruginosa showed a greater increase in resistance to gentamicin than to the other three aminoglycosides. $E$. coli required more transfers to reach the same degree of resistance than did the other two species. Reversion to greater susceptibility to gentamicin took place after serial passage on antibiotic-free media.

'Wild' gentamicin-resistant strains showed no such proportionality of resistance to kanamycin, $\vec{\oplus}$ neomycin, or streptomycin. But many of these strains showed a proportional increase in resistance $\forall$ to tobramycin.

Acquired resistance of Gram-negative bacilli to gentamicin associated with its clinical usage has been reported from various centres (Greene et al., 1973; Eykyn and Phillips, 1975; Seal and Strangeways, 1975; Shafi and Datta, 1975). When stated, the sensitivity of these organisms to tobramycin, an aminoglycoside antibiotic which has a very similar spectrum of activity, has been variable. The present study was undertaken to investigate further the cross-resistance between these two and other aminoglycosides. Strains habituated to gentamicin in the laboratory and 'wild' gentamicin-resistant strains were examined for cross-resistance to other aminoglycosides and to some unrelated agents.

\section{Material and methods}

\section{BACTERIAL STRAINS}

Ten strains each of E. coli, Staph. aureus, and Ps. aeruginosa, all sensitive to $4 \mu \mathrm{g}$ or less gentamicin per $\mathrm{ml}$, were isolated from clinical material in the Medical Microbiology Department of St Bartholomew's Hospital.

Sixty-eight strains of Gram-negative bacteria Present address:

'The London Hospital, London E1 1BB

${ }^{2}$ Department of Microbiology, University of Nottingham, City Hospital, Nottingham NG5 1PH

Received for publication 26 January 1977 resistant to $8 \mu \mathrm{g}$ or more gentamicin per $\mathrm{ml}$ were collected from various hospitals in the London area. They were identified by API systems as Pseudomonas $\overrightarrow{\vec{O}}$ spp (47), E. coli (2), Klebsiella spp (4), Proteus spp (3), Providence spp (6), Flavobacter spp (2), Alcaligenes spp (2), and Acinetobacter spp (2).

INDUCED RESISTANCE

Gradient plates were prepared using Oxoid DST agar in which the antibiotic-containing wedge included gentamicin at concentrations of $2 \mu \mathrm{g}, 8 \mu \mathrm{g}$, $\frac{3}{3}$ $32 \mu \mathrm{g}$, and $128 \mu \mathrm{g}$. Overnight broth cultures $\left(37^{\circ} \mathrm{C}\right)$ of each strain were first flooded onto whole plates containing $2 \mu \mathrm{g}$ gentamicin per $\mathrm{ml}$ and surplus fluid $\frac{D}{0}$ was removed aseptically. After 18 hours' incubation the edge of growth was swept with a loop and applied $N$ to a fresh gradient plate containing the same genta- $N$ micin concentration, spread with a dry cotton-wool $\mathcal{N}^{\circ}$ swab, and incubated overnight. The process was $\omega$ repeated until growth was obtained from the whole plate. A sample of this culture was removed for $\stackrel{\circ}{c}$ storage on a slope of Oxoid blood-agar base (BAB) containing the concentration of gentamicin to which ? it had been habituated, and serial passage was continued on gradient plates containing the next $\stackrel{\vec{D}}{\mathrm{D}}$ higher concentration of gentamicin. In this way 10 strains each of Staph. aureus, E. coli, and Ps. aeruginosa were passaged until growth was obtained 
on gradient plates containing $128 \mu \mathrm{g}$ of gentamicin per $\mathrm{ml}$, so that from each parent strain resistant variants growing in the presence of $2 \mu \mathrm{g}, 8 \mu \mathrm{g}, 32 \mu \mathrm{g}$, and $128 \mu \mathrm{g}$ gentamicin per $\mathrm{ml}$ were derived.

DETERMINATION OF MINIMAL INHIBITORY CONCENTRATIONS

Scrial doubling dilutions of gentamicin, tobramycin, streptomycin, neomycin, and kanamycin were made in DST agar (Oxoid) and the plates were seeded by means of a multiple inoculation device (Denly-Tech Ltd, Billingshurst, Sussex) with an 18-hour nutrient broth (Oxoid) culture diluted to contain $10^{4}$ colonyforming units $/ \mathrm{ml}$. The number of colony-forming units on the control plates was approximately 20 . The minimal inhibitory concentration (MIC) was taken to be the lowest concentration of antibiotic that allowed the growth of less than three colonies after 18 hours' incubation. Each parent strain and the resistant progenies were tested together on the same series of plates.

\section{GROWTH CURVES}

The growth curves of four parent strains and their derived resistant $(128 \mu \mathrm{g} / \mathrm{ml})$ variants were compared by continuous turbidimetric monitoring before and after 20 serial subcultures on antibiotic-free agar slopes. These growth studies were performed in 'complete' broth (Greenwood and O'Grady, 1973) using the multichannel opacity device described by Mackintosh et al. (1973).

\section{Results}

\section{HABITUATION STUDIES}

\section{Comparison with other aminoglycosides}

The number of transfers required to achieve various degrees of resistance to gentamicin is shown in Table 1. E. coli required more transfers to reach the same degree of resistance than did Ps. aeruginosa or Staph. aureus.

After training to various degrees of resistance to gentamicin, the relationship between MICs of

Table 1 Average number of transfers required to achieve various degrees of resistance to gentamicin

\begin{tabular}{llll}
\hline Bacterial species & \multicolumn{3}{l}{$\begin{array}{l}\text { Average number of transfers required to achieve } \\
\text { MIC gentamicin of: }\end{array}$} \\
\cline { 2 - 4 } & $2-8 \mu \mathrm{g} / \mathrm{ml}$ & $16-64 \mu \mathrm{g} / \mathrm{ml}$ & $\geqslant 128 \mu \mathrm{g} / \mathrm{ml}$ \\
\hline E. coli & $3(2-9)^{*}$ & $9(2-16)$ & $18(15-31)$ \\
Staph. aureus & $3(2-7)$ & $4(2-9)$ & $11(7-15)$ \\
Ps. aeruginosa & $3(2-5)$ & $7(3-9)$ & $13(11-19)$ \\
\hline
\end{tabular}

*Figures in parentheses show the range. gentamicin and tobramycin is shown in Fig. 1 and the relationship between MICs of gentamicin and kanamycin in Fig 2. A generally linear relationship was obtained but tobramycin was found to be two to four times more active than gentamicin against $P$ s. aeruginosa and slightly less active against Staph. aureus, E. coli, and Klebsiella spp. The MICs of gentamicin and neomycin, and gentamicin and streptomycin, showed a similar linear relationship although kanamycin, neomycin, and streptomycin were less active against $P$ s. aeruginosa than against the other organisms tested.

\section{Extent of increase in induced resistance}

The extent of the corresponding increase in resistance to tobramycin, neomycin, kanamycin, and streptomycin (resistance index) was calculated from the ratio of the MICs of the antibiotic for the parent strain and derived resistant variant multiplied by the reciprocal of the corresponding ratio for gentamicin. For example, if a strain was originally sensitive to $1 \mu \mathrm{g}$ gentamicin per $\mathrm{ml}$ and $2 \mu \mathrm{g}$ neomycin per $\mathrm{ml}$ and the habituated variant was inhibited by $128 \mu \mathrm{g}$ gentamicin per $\mathrm{ml}$ and $256 \mu \mathrm{g}$ neomycin per $\mathrm{ml}$, the resistance index for neomycin would be $2 / 256 \times$ $128 / 1=1$. If the relative increase in the resistance to gentamicin were greater than that to the other aminoglycoside the index would be more than 1 , and if it were less, the index would be less than 1 . The numbers of strains of E. coli, Staph.aureus, and $P s$. aeruginosa showing various resistance indices calculated in this way are shown in Table 2. The majority of $E$. coli strains showed the same degree of resistance to neomycin, tobramycin, and kanamycin as to gentamicin (resistance index $=1$ ). However, most strains of Staph. aureus and Ps. aeruginosa showed a greater increase in resistance to gentamicin than to these three aminoglycosides (resistance index between 2 and 16). The relative increase in resistance to streptomycin appeared the smallest among the aminoglycosides tested against all three species.

\section{Stability of induced resistance}

Two representative strains of each species habituated to high levels of gentamicin were retested in conventional MIC titrations after 20 serial subcultures on antibiotic-free nutrient agar slopes. Reversion to greater susceptibility was demonstrated in all cases, but complete reversion to the original sensitivity was not observed. The strains of E. coli and Staph. aureus were also investigated by continuous turbidimetric monitoring; Ps. aeruginosa does not lend itself to investigation by this means (Greenwood, 1977). Variants of E. coli and Staph. aureus that had been habituated to high levels of gentamicin grew more slowly than their parent strains but after 20 


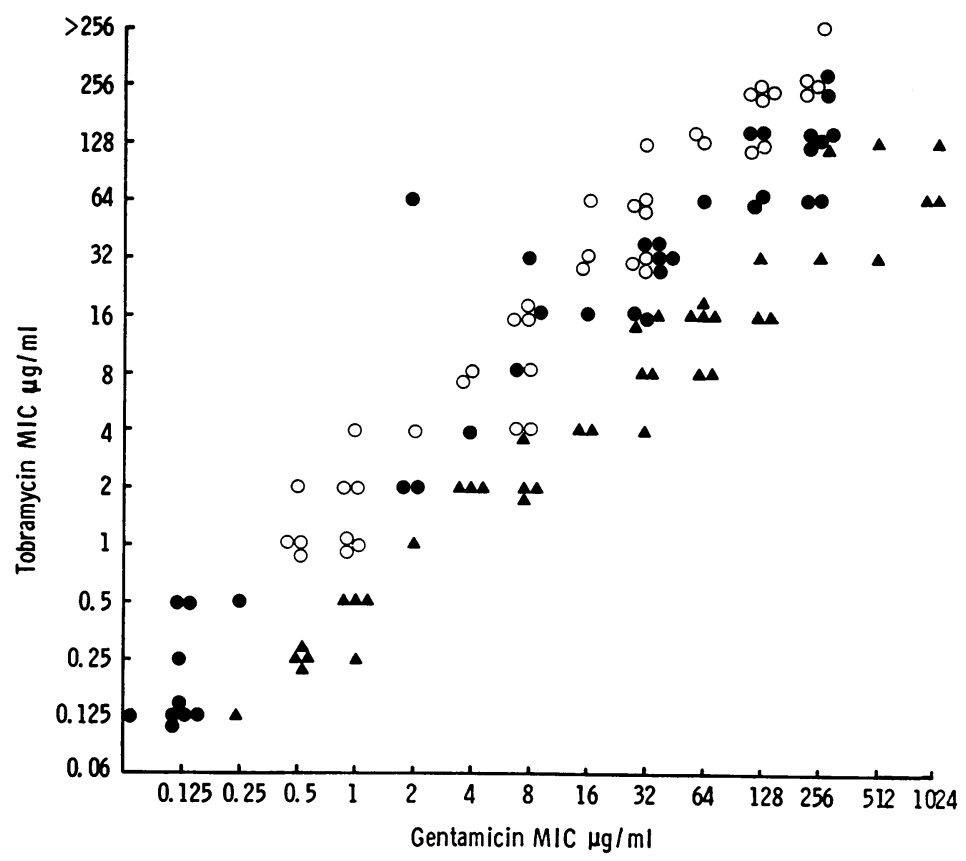

Fig. 1 Comparison of MICs of gentamicin and tobramycin at different stages of development of resistance. Coefficients of correlation. E. coli, $0.96(\mathrm{O})$; Staph. aureus, $0.96(\Theta)$; Pseudomonas aeruginosa, $0.98(\Delta)$

Fig. 2 Comparison of MICs of gentamicin and kanamycin at different stages of development of resistance. Coefficients of correlation: E, coli, $08.89(\mathrm{O})$; Staph. aureus, $0.96(0)$; Pseudomonas aeruginosa $0.91(\Delta)$

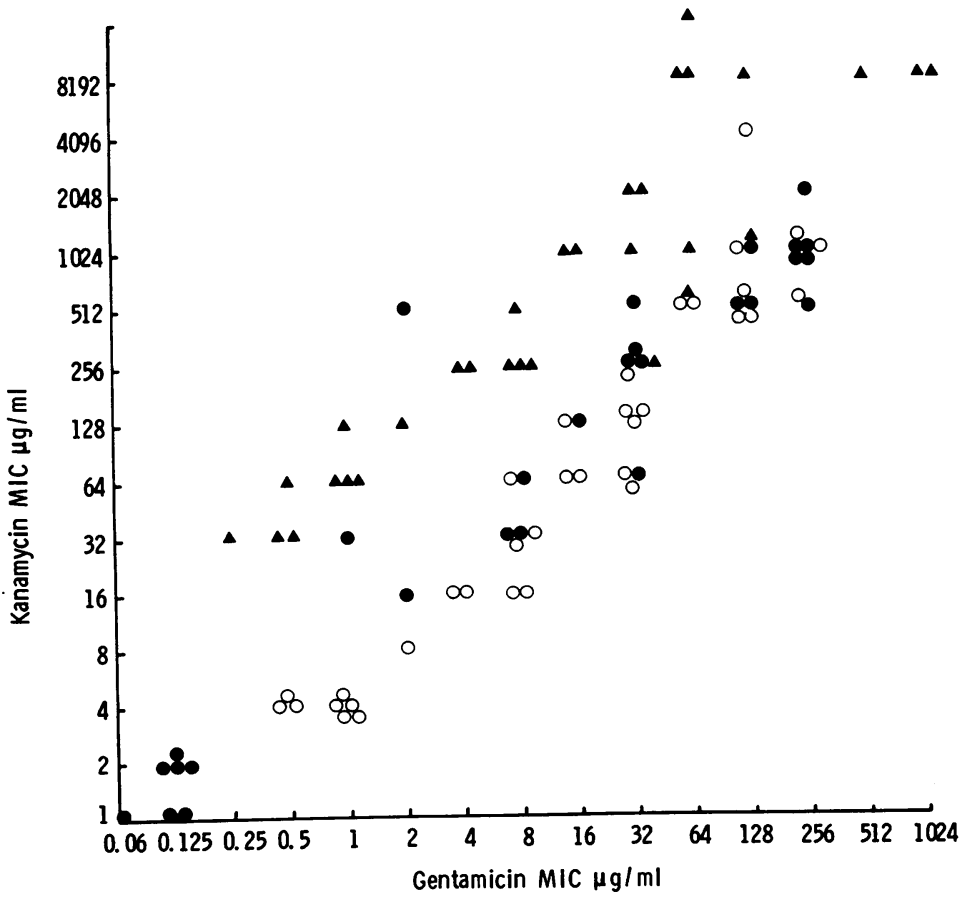


Table 2 Relationship of resistance to other aminoglycosides of strains habituated to gentamicin

\begin{tabular}{lllllll}
\hline \multirow{2}{*}{ Organism } & Aminoglycoside & \multicolumn{4}{l}{ No. of strains having resistance index } \\
\cline { 3 - 7 } & & $0 \cdot 25-0 \cdot 5$ & 1 & $2-4$ & $8-16$ & $\geqslant 32$ \\
\hline \multirow{2}{*}{ E. coli } & Neomycin & 3 & 7 & 3 & 0 & 0 \\
& Tobramycin & 2 & 10 & 3 & 0 & 0 \\
& Streptomycin & 0 & 0 & 4 & 8 & 2 \\
& Kanamycin & 1 & 10 & 2 & 0 & 0 \\
\multirow{5}{*}{ Staph. aureus } & Neomycin & 1 & 1 & 4 & 0 & 0 \\
& Tobramycin & 0 & 1 & 7 & 2 & 0 \\
& Streptomycin & 0 & 1 & 1 & 2 & 4 \\
& Kanamycin & 0 & 1 & 5 & 2 & 0 \\
& Neomycin & 0 & 1 & 6 & 1 & 0 \\
& Tobramycin & 0 & 2 & 5 & 3 & 0 \\
& Streptomycin & 0 & 0 & 1 & 4 & 4 \\
& Kanamycin & 0 & 1 & 2 & 3 & 0 \\
\hline
\end{tabular}

serial subcultures in the absence of antibiotic these variants exhibited an intermediate growth rate (Fig. 3). The corresponding MIC levels of these revertants were also intermediate between those of the parent and the resistant variant: in the examples shown in Fig. 3, the MIC of gentamicin for the parent of $E$. coli was $0.5 \mu \mathrm{g}$ per $\mathrm{ml}$, that of the resistant variant $256 \mu \mathrm{g}$ per $\mathrm{ml}$, and that of the revertant $8 \mu \mathrm{g}$ per ml. Similarly, the MIC of gentamicin for the parent Staph. aureus was $0.125 \mu \mathrm{g}$ per $\mathrm{ml}$, that of the variant $256 \mu \mathrm{g}$ per $\mathrm{ml}$, and that of the revertant $16 \mu \mathrm{g}$ per $\mathrm{ml}$.

Three strains of Staph. aureus were found to have reverted to partial sensitivity despite storage in antibiotic-containing agar slopes. The fall in MICs of gentamicin was accompanied by a reduction in MICs of the other four aminoglycosides except in one case in which resistance to tobramycin was maintained.

\section{Other antimicrobial agents}

The sensitivities to tetracycline, chloramphenicol, and polymyxin of all the variants habituated to resistance to at least $128 \mu \mathrm{g}$ gentamicin per $\mathrm{ml}$ and their respective parent strains were compared by titration. No significant differences were found.

'WILD' STRAINS

The MIC of gentamicin was compared with that of four other aminoglycosides for 47 strains of Pseudomonas spp and 21 strains of other aerobic Gramnegative bacteria. A random scatter was obtained with kanamycin (Fig. 4). A similar scatter was found with neomycin and streptomycin but the relationship between gentamicin and tobramycin resistance was different (Fig. 5). When MICs of tobramycin were plotted against those of gentamicin, tobramycin appeared to be two to four times more active against the majority of organisms. Three gentamicinresistant Pseudomonas strains with MIC $\geqslant 32 \mu \mathrm{g}$ per $\mathrm{ml}$ were encountered which remained fully sensitive to tobramycin.
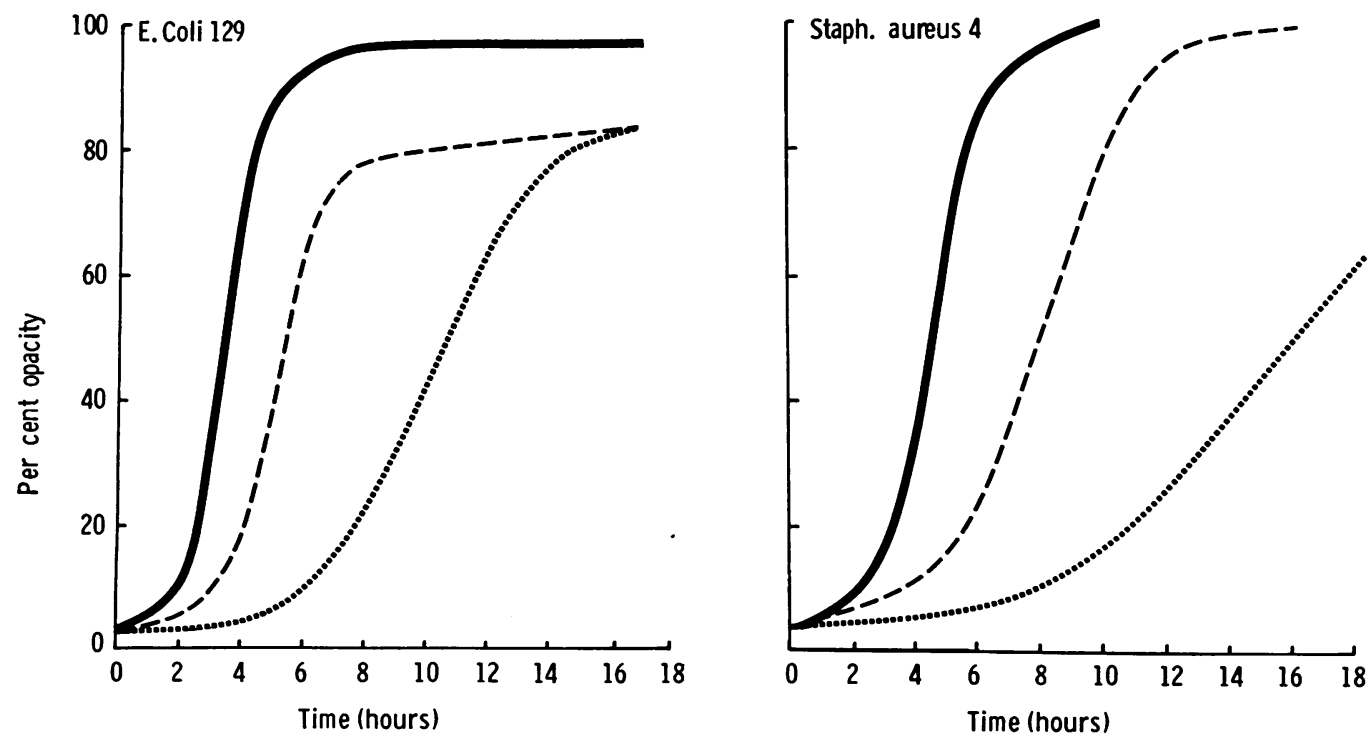

Fig. 3 Growth curves of E. coli and Staph. aureus in complete broth obtained by continuous turbidimetric monitoring. $-=$ Parent strain ; . . . = resistant variant $; \ldots+-=$ resistant variant after 20 subcultures in antibiotic-free media. 


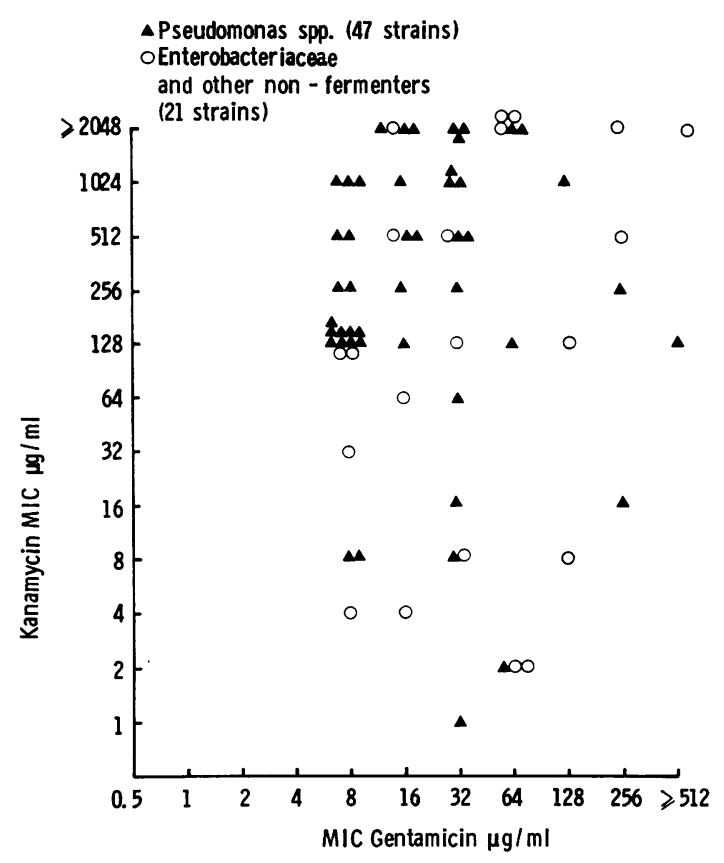

Fig. 4 A comparison of MICs of gentamicin and kanamycin in wild strains.

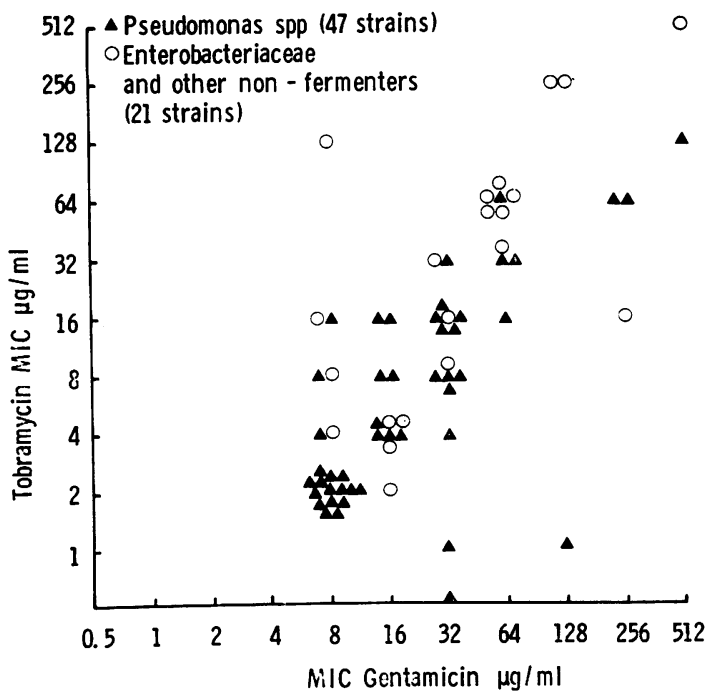

Fig. 5 A comparison of MICs of tobramycin and gentamicin in wild strains.

\section{Discussion}

Complete cross-resistance between neomycin, streptomycin, and kanamycin has been reported by many workers in 'wild' and laboratory-derived resistant strains of bacteria (Kunin et al., 1958; Barber and Waterworth, 1966; Garrod et al., 1973). However, possible cross-resistance between these early antibiotics and newer ones (gentamicin and tobramycin) has not been reported. Cross-resistance to tobramycin among strains habituated to gentamicin has been demonstrated (Weinstein et al., 1971; Waterworth, 1972), but the patterns of cross-resistance emerging during the training procedure were not reported. The present findings indicate that there is complete cross-resistance between kanamycin, streptomycin, neomycin, and tobramycin at all stages of the habituation procedure when strains of $E$. coli, $P s$. aeruginosa, and Staph. aureus are trained to resistance to gentamicin. The degree of crossresistance obtained is generally directly proportional to the degree of resistance induced to gentamicin but the ratio appears to vary with species and the aminoglycoside, the smallest increase in crossresistance being found in streptomycin.

In contrast, 'wild' gentamicin-resistant strains showed no such proportionality of resistance to kanamycin, neomycin or streptomycin, but many of these strains did show a proportional increase in resistance to tobramycin. Gentamicin is more active than tobramycin against sensitive strains of $E$. coll and Staph. aureus but tobramycin is two to four times more active than gentamicin against gentamicin-sensitive strains of Pseudomonas spp (Waterworth, 1972; Molavi et al., 1973; Klastersky et al., 1973; Wretlind et al., 1974). When 47 gentamicinresistant strains of Pseudomonas spp were examined in the present study, this superiority of tobramycin was found to extend to the majority of resistant strains. Three wild strains were encountered which were resistant to $\geqslant 32 \mu \mathrm{g}$ gentamicin per $\mathrm{ml}$ but sensitive to $1.0 \mu \mathrm{g}$ tobramycin per $\mathrm{ml}$ and, conversely, one strain resistant to $128 \mu \mathrm{g}$ tobramycin per $\mathrm{ml}$ was inhibited by $8 \mu \mathrm{g}$ gentamicin per $\mathrm{ml}$. Such organisms which do not exhibit cross-resistance between gentamicin and tobramycin may have different mechanisms of resistance from the many strains which show cross-resistance. Similar patterns, observed by Crowe and Sanders (1972), were apparently related to the presence of different $\mathbf{R}$ factor mediated aminoglycoside-inactivating enzymes (Jacoby, 1974; Benveniste and Davies, 1973).

It has been suggested that laboratory-induced resistance to aminoglycosides arises from the selection of mutants (Waterworth, 1972). The instability of such resistance suggests rather that resistant variants have a reduced permeability to aminoglycosides and/or that they possess a phenotypically altered ribosome (Davies, 1971). The permeability hypothesis would seem to be the more 
attractive of the possibilities in view of the linear relationship between the MICs of gentamicin and the amount of surface lipid that has been demonstrated in wild and induced gentamicin-resistant Pseudomonas strains (Pechey and James, 1973). Whatever the resistance mechanism, it appears to be restricted to aminoglycosides because sensitivity to tetracycline, chloramphenicol, and polymyxin remained unchanged.

In addition, adaptation to resistance appears to be accompanied by a reduction in growth rate in broth and frequently variation in colonial morphology on solid media. Such altered growth characteristics are in keeping with the findings of Weinstein et al. (1971) that Pseudomonas strains lose their virulence for mice and show nutrient dependence when trained to resistance in the laboratory.

Many instances of resistance to gentamicin emerging during therapy have been reported (Greene et al., 1973; Eykyn and Phillips, 1975; Seal and Strangeways 1975; Shafi and Datta, 1975), and some strains have been observed to become less resistant after cessation of gentamicin therapy (Seal and Strangeways, 1975; Snelling et al., 1971). Gentamicinresistant Pseudomonas strains isolated after oral gentamicin therapy have been reported to be less invasive than the sensitive strains isolated before institution of gentamicin therapy, even in patients with agranulocytosis (Greene et al., 1973).

In vivo, $\mathrm{R}$ factor mediated resistance undoubtedly plays a part in the emergence of resistance in some cases (Shafi and Datta, 1975; Richmond et al., 1975), but in circumstances where this type of resistance has no opportunity to occur a mechanism similar to that demonstrated in the laboratory may operate. This presumably is most likely to occur with those aminoglycosides in which levels achieved on conventional therapeutic regimes do not greatly exceed the MIC. However, even if resistance does emerge by this mechanism the epidemiological significance of such strains may not be as great as is feared because of the attenuated nature of these bacteria and the relative instability of the resistance induced.

We are indebted to Professor F. O'Grady for his advice throughout, and to the Microbiology Quality Control Departments of Roussel Laboratories Ltd, Swindon, England for identification of bacterial strains.

\section{References}

Barber, M. and Waterworth, P. M. (1966). Activity of gentamicin against Pseudomonas and hospital staphylococci. British Medical Journal, 1, 203-205.

Benveniste, R. and Davies, J. (1973). Mechanisms of antibiotic resistance in bacteria. Annual Review of
Biochemistry, 42, 471-506.

Crowe, C. C. and Sanders, E. (1972). Is there complete cross-resistance of gram-negative bacilli to gentamicin and tobramycin? Antimicrobial Agents and Chemotherapy, 2, 415-416.

Davies, J. (1971). Bacterial resistance to aminoglycoside antibiotics. Journal of Infectious Diseases, 124, S7-S10.

Eykyn, S. and Phillips, I. (1975). Gentamicin-resistant Pseudomonas aeruginosa (Letter). Lancet, 1, 861-862.

Garrod, L. P., Lambert, H. P., and O'Grady, F. (1973). Antibiotic and Chemotherapy. 4th edition, p. 118. Churchill Livingstone, Edinburgh and London.

Greene, W. H., Moody, M., Schimpff, S., Young, V. M., and Wiernik, P. H. (1973). Pseudomonas aeruginosa resistant to carbenicillin and gentamicin. Annals of Internal Medicine, 79, 684-689.

Greenwood, D. (1977). Response profiles: a method of evaluating the activity of $B$-lactam antibiotics against enterobacteria. Chemotherapy, 23, 11-18.

Greenwood, D. and O'Grady, F. (1973). Comparison of the responses of Escherichia coli and Proteus mirabilis to seven B-lactam antibiotics. Journal of Infectious Diseases, 128, 211-222.

Jacoby, G. A. (1974). Properties of an $\mathbf{R}$ plasmid in Pseudomonas aeruginosa producing amikacin (BB-K8), butirosin, kanamycin, tobramycin, and sisomicin resistance. Antimicrobial Agents and Chemotherapy, 6, 807-810.

Klastersky, J., Daneau, D., and de Maertelaer, V. (1973). Comparative study of tobramycin and gentamicin with special reference to anti-Pseudomonas activity. Clinical Pharmacology and Therapeutics, 14, 104-111.

Kunin, C. M., Wilcox, C., Najarian, A., and Finland, M. (1958). Susceptibility and cross-resistance of bacteria to four related antibiotics: kanamycin, paromomycin, neomycin and streptomycin. Proceedings of the Society for Experimental Biology and Medicine, 99, 312-316.

Mackintosh, I. P., O'Grady, F., Greenwood, D., Watson, B. W., Crichton, T. C., Piper, R., and Ferrer, A. (1973). A twelve channel bacterial growth monotoring system. Biomedical Engineering, 8, 514-515 and 526.

Molavi, A., Barza, M., Cole, W., Berman, H., and Weinstein, L. (1973). In vitro assessment of tobramycin, a new aminoglycoside with anti-Pseudomonas activity. Chemotherapy, 18, 7-16.

Pechey, D. T. and James, A. M. (1973). Surface lipid of cells of Pseudomonas aeruginosa and its relation to gentamicin-resistance. Biomedicine, 19, 127-129.

Richmond, A. S., Simberkoff, M. S., Rahal, J. J. Jr., and Schaefler, S. (1975). R-factors in gentamicin-resistant organisms causing hospital infection. Lancet, 2, 1176-1178.

Seal, D. V. and Strangeways, J. E. M. (1975). Resistant pseudomonads in a neurosurgical unit (Letter). Lancet, 1, 48-49.

Shafi, M. S. and Datta, N. (1975). Infection caused by Proteus mirabilis strains with transferable gentamicinresistance factors. Lancet, 1, 1355-1357.

Snelling, C. F. T., Ronald, A. R., Cates, C. Y., and Forsythe, W. C. (1971). Resistance of Gram-negative bacilli to gentamicin. Journal of Infectious Diseases, 124, S264-S270. 
Waterworth, P. M. (1972). The in-vitro activity of tobramycin compared with that of other aminoglycosides. Journal of Clinical Pathology, 25, 979-983.

Weinstein, M. J., Drube, C. G., Moss, E. L., Jr., and Waitz, J. A. (1971). Microbiologic studies related to bacterial resistance to gentamicin. Journal of Infectious
Diseases, 124, S11-S17.

Wretlind, B., Nord, C.-E., and Wadström, T. (1974). In vitro sensitivity of isolates of Pseudomonas aeruginosa to carbenicillin, gentamicin, tobramycin, and some other antibiotics. Scandinavian Journal of Infectious Diseases, 6, 49-52.

\section{The July 1977 Issue}

\section{THE JULY 1977 ISSUE CONTAINS THE FOLLOWING PAPERS}

Strains of Achromobacter xylosoxidans from clinical material B. HOLMES, J. J. S. SNELL, AND S. P. LAPAGE

Lack of evidence for mutation to erythromycin resistance in clinical strains of Staphylococcus aureus R. W. LACEY

Comparison of coagulase, deoxyribonuclease (DNase), and heat-stable nuclease tests for identification of Staphylococcus aureus ROSALIE E. MENZIES

Recovery of anaerobic bacteria from small inocula: a model for blood culture studies J. G. COLLEE, B. I. DUERDEN, AND R. BROWN

Multiplication of contaminant bacteria in urine and interpretation of delayed culture D. B. WHELDON AND MARY SLACK

Novobiocin and the differentiation of peptococci and peptostreptococci M. W. D. WREN, C. P. ELDON, AND G. H. DAKIN

Simplified method for the rubella haemagglutination inhibition screening test P. P. MORTIMER, SUSAN M. JORDAN, AND I. V. SMITH

Comparison between the automated reagin test and reagin screen test methods of VDRL screening tests for syphilis in use in a routine laboratory ROSEMARY D. SIMON AND ALAN M. PEACOCK

Hydroxyproline excretion in infantile gastroenteritis R. H. J. BEGENT AND H. P. LAMBERT

Comparison of thyroid stimulating hormone and triiodothyronine response to thyrotrophin releasing hormone in the assessment of thyroid status C. R. SQUIRE AND T. M. D. GIMLETTE
The erroneous haemoglobin-hyperlipidaemia relationship P. D. NICHOLLS

West Midlands regional quality control scheme for haematology I. D. O. FREW, T. W. ROOME, AND B. ASHMAN

Measurement of serum folate: experience with ${ }^{75}$ Se-selenofolate radioassay IAN JOHNSON, HUGH GUILFORD, AND MICHAEL ROSE

Platelet adhesiveness in young patients with ischaemic stroke SUBHASH C. SHARMA, G. P. VIJAYAN, M. L. SURI, AND H. N. SETH

Cytochemical reactions of normal and neoplastic lymphocytes F. R. DAVEY, S. J. HUNTINGTON, J. MACCALLUM, AND J. M. MACMATH

Alveolar rhabdomyosarcoma presenting as subacute intravascular coagulation A. ELDOR, ELLA NAPARSTEK, J. H. BOSS, AND SHOSHANA BIRAN

Reaction of human smooth muscle autoantibody with gastric parietal cells: a pitfall in the diagnosis of parietal cell autoantibody R. CEREDIG AND B. H. TOH

$\mathrm{HB}_{\mathrm{S}} \mathrm{Ag}$ and $\mathrm{HB}_{\mathrm{C}} \mathrm{Ag}$ in the livers of asymptomatic hepatitis $B$ antigen carriers E. TAPP AND D. M. JONES

Two cases of alpha chain disease from Nigeria J. T. WHICHER, A. AJDUKIEWICZ, AND J. D. DAVIES

\section{Technical method}

Application of the Papanicolaou stain to routine histological examination of placenta D. DiFRUSCIO AND D. J. DESA

\section{Letters to the Editor}

Book reviews

Copies are still available and may be obtained from the PUBLISHING MANAGER, BRITISH MEDICAL ASSOCIATION, TAVISTOCK SQUARE, LONDON WC1H 9JR, price $£ 3.00$, including postage 